ORIGINAL ARTICLE

\title{
Illumination of $x$-rays: the usual lights exposed
}

\section{G R J C Blackshaw, J A Gostling, B N Appleton, N Pearce, G V Thomas, W G Lewis}

Postgrad Med J 2003;79:99-100

See end of article for authors' affiliations

Correspondence and requests for reprints to: $\mathrm{Mr}$ W G Lewis, Royal Gwent Hospital, Cardiff Road, Newport NP20 2UB, UK; wyn.lewis@ gwent.wales.nhs.uk

Submitted 30 September 2002

Accepted

3 December 2002

\begin{abstract}
Aims: Faced with pressure of work and limited resource, doctors frequently use the nearest available light to examine $x$-ray films. The aim of this study was to examine the relative intensities of hospital light sources, and to compare these with the light intensity guidelines (1500 to 3000 candelas) of the British Institute of Radiology.

Methods: The relative intensities of seven hospital light sources were examined using a standard light meter at a constant $30 \mathrm{~cm}$ from the source. A control group of 10 individual consultant's $x$-ray viewing boxes were compared with six other ward based light sources.

Results: Only two light sources approached the British Institute of Radiology light intensity $x$-ray viewing criteria: the $x$-ray viewing boxes of consultant radiologists with a median light intensity of 3503 candelas $\left(\chi^{2}=13.3, \mathrm{df} 1 ; p=0.0001\right)$, and daylight from north facing windows with a median of 1464 candelas when overcast $\left(\chi^{2}=8.571, \mathrm{df} 1 ; p=0.003\right)$ and 4669 candelas in sunshine $\left(\chi^{2}=6.364\right.$, df 1 ; $\mathrm{p}=0.0001)$.

Conclusion: Few hospital light sources met the British Institute of Radiology guidelines. The long held high regard of artists for northern light appears justified even in the environment of a British district general hospital.
\end{abstract}

$\mathrm{F}$ aced with pressure of work and limited resource, hospital doctors frequently use the nearest available light source, often a window, to examine and interpret patients' $x$-ray films. Arguably, diagnostic inaccuracies may result from such practice. Indeed it was recently suggested that daylight from a hospital window provides suboptimal illumination when compared with the light intensity from an $x$-ray viewing box.

The British Institute of Radiology guidelines quote values of 1500 to 3000 candelas as the ideal range of light intensity required to view and interpret $x$-rays. ${ }^{2}$ The aim of this study was to examine the relative intensities of the light sources that are commonly available in hospitals, with which to view $x$-ray films, and to compare the intensities of these light sources with the light intensity levels recommended by the British Institute of Radiology.

\section{METHODS}

Light intensity was measured using a standard light meter (Profisix, Gossen Foot-un, Lichtmebtecnik, Nurnberg, Germany) at a constant $30 \mathrm{~cm}$ from the source. A control group of 10 individual $x$-ray viewing boxes (Wardray Premise
Limited, Hampton Court Estate, Surrey, UK), each (four 18 watt bulbs) part of a bank of eight, present in the offices of 10 consultant radiologists, were compared with six other light sources ( 10 of each type) available on a district general hospital ward (Royal Gwent Hospital, Newport, South Wales, UK, longitude $3^{\circ}$ west, latitude $51^{\circ} 35^{\prime}$ north). The light sources were as follows: ward $x$-ray viewing boxes (H A West [X-ray] Limited, 41 Watson Crescent, Edinburgh, UK, four 18 watt bulbs), ward ceiling lights ( 36 watts fluorescent light tubes), and ward windows facing south, north, east, and west. Ward window daylight intensity measurements were performed at 09:00 hours on two separate days (weather overcast and sunny) during December 2001. All luminant surfaces and windows were cleaned immediately before the light readings were taken. The relationship of illuminance (E, measured in lux) to light intensity (B, measured in candelas) is given by the equation:

$$
\mathrm{E}=\mathrm{r}^{2} \mathrm{~B} /\left(\mathrm{r}^{2}+\mathrm{d}^{2}\right)
$$

where $r$ represents the radius of the disc of the light source, and $\mathrm{d}$ represents the distance from the light source to the photometer $(30 \mathrm{~cm})$.

\begin{tabular}{lll} 
Table 1 Median light intensity; figures are median (range) \\
\hline Light source & Illuminance (lux $\times 1000)$ & Light intensity (candela) \\
\hline Consultant radiologists' viewing boxes & $11.0(9.17-14.67)$ & $3503(2919-4671)$ \\
Ward viewing boxes & $1.05(0.58-2.45)$ & $334(185-780)^{*}$ \\
Ward ceiling light & $2.2(18.3-29.3)$ & $7020(5850-9359)^{*}$ \\
Ward window: sunshine & $2.3(1.4-4.6)$ & $742(445-1464)^{*}$ \\
$\quad$ South facing & $14.6(9.17-22.0)$ & $4669(2918-7004)^{*}$ \\
North facing & $36.67(18.3-44.0)$ & $11673(5836-14008)^{*}$ \\
East facing & $22.0(18.3-29.3)$ & $7003(5838-9338)^{*}$ \\
West facing & $2.3(1.87-2.8)$ & $742(594-891)^{*}$ \\
Ward window: overcast & $4.6(2.8-9.17)$ & $1464(891-2918)^{* *}$ \\
$\quad$ South facing & $1.87(1.4-2.33)$ & $594(445-742)^{*}$ \\
$\quad$ North facing & $2.33(1.87-2.8)$ & $742(594-891)^{*}$ \\
East facing &
\end{tabular}




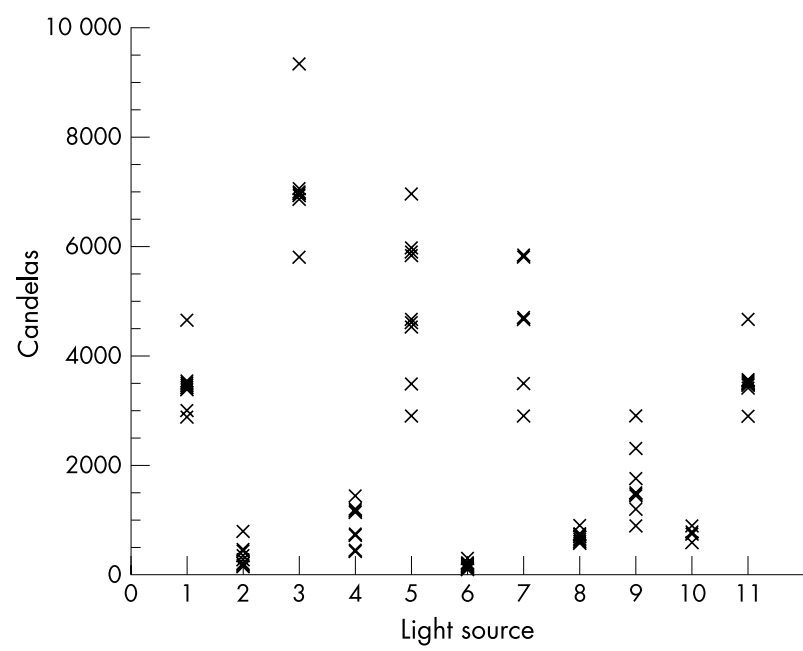

Figure 1 Scatter plot of measured light intensity relative to the source. Key: 1, x-ray view box of consultant radiologist; 2, $x$-ray view box of hospital wards; 3 , fluorescent ceiling light; 4 , south window: sunshine; 5 , north window: sunshine; 6 , east window: sunshine; 7 , west window: sunshine; 8 , south window: overcast; 9 , north window: overcast; 10, east window: overcast; 11, west window: overcast.

\section{Statistical analysis}

Statistical analysis for non-parametric data was used. ${ }^{3}$ Data analysis was carried out with the Statistical Package for Social Sciences version 11 (SPSS, Chicago, Illinois, USA).

\section{RESULTS}

The relative median intensities of the individual light sources are shown in table 1 , and all the measured data are shown as a scatter plot in fig 1 . The light sources that were consistently closest in intensity to the British Institute of Radiology guidelines for viewing radiographs were the $x$-ray viewing boxes of consultant radiologists (median 3503 candelas, $\chi^{2}=13.3$, df 1; $\mathrm{p}=0.0001)$, and daylight from north facing hospital windows (median 1464 candelas (overcast), $\chi^{2}=8.571$, df $1 ; p=0.003$ and median 4669 candelas (sunshine), $\chi^{2}=16.364, \mathrm{df} 1$; $\mathrm{p}=0.0001$ ).

\section{DISCUSSION}

"Light—God's eldest daughter is a principal beauty" (Thomas Fuller 1661).

It is assumed widely and asserted confidently that an $x$-ray viewing box provides the only adequate source of light with which to view and interpret $x$-ray films. ${ }^{14}$ This assumption is challenged by the results of our study. Indeed, the only two sources of light which were consistently closest to the British Institute of Radiology guidelines were the consultant radiologists' viewing boxes and daylight from a north facing hospital window.

The relationship of illuminance to light intensity is proportional to the radius of the disc of light, the distance of the photometer from the light, and also the ambient light. ${ }^{5}$ This complex equation may explain why the hospital ward viewing boxes failed to meet the light intensity guidelines. In contrast, the quality of daylight from a northerly direction in the northern hemisphere of the world, and conversely from a southerly direction in the southern hemisphere has long been favoured by artists and photographers alike, for its even intensity and absence of shadow. ${ }^{5}$ In the early days of photography, when suitable artificial light was a scarce resource, the photographer who wanted to work indoors required a specially adapted "daylight studio" admitting the maximum amount of daylight, but not direct sunlight. The majority of such studios had a glass roof facing north at a minimum angle of $60^{\circ}$ to prevent the direct intrusion of sunlight.

In conclusion, the frequently practised and time saving manoeuvre of holding radiographs up to the nearest bright light need not necessarily constitute bad medical practice. If the results of this study are representative, doctors in the northern hemisphere (latitudes of around $50^{\circ}$ ) without ready access to an adequate $x$-ray viewing box should feel confident that other convenient sources of light, preferably daylight from a north facing window, provides light of consistent and adequate intensity regardless of the prevailing weather conditions with which to illuminate and interpret an $x$-ray film.

\section{Authors' affiliations}

G R J C Blackshaw, J A Gostling, B N Appleton, W G Lewis, Department of Surgery, Royal Gwent Hospital, Newport N Pearce, Department of Medical Photography, Royal Gwent Hospital Newport

G V Thomas, Department of Radiology, Royal Gwent Hospital, Newport

\section{REFERENCES}

1 Maxwell-Armstrong C, Lloyd J, Abercrombie J. A comparison of junior hospital doctors interpretation of acute radiographs using an $X$-ray box and a window. Ann R Coll Engl $2001 ; 83: 435-6$.

2 Hartmann E, Stieve FE. Quality control of radiographic illuminators and associated viewing equipment. British Institute of Radiology report 18. London: BIR, 1989: 135-7.

3 Altman DG. Practical statistics for medical research. London: Chapman and Hall, 1991.

4 Rill LN, Huda W, Gkanatsios NA. View box luminance measurements and their effect on reader performance. Academic Radiology $1999 ; 6: 521-9$

5 Mannheim LA, Buckmaster D, Purves F, et al. The focal encyclopedia of photography. London: Focal Press, 1969. 